\title{
Mechanistic Study of the Conversion of Superoxide to Oxygen and Hydrogen Peroxide in Carbon Nanoparticles
}

Almaz S. Jalilov, ${ }^{\dagger}$ Chenhao Zhang, ${ }^{\dagger}$ Errol L. G. Samuel, ${ }^{\dagger}$ William K. A. Sikkema, ${ }^{\dagger}$ Gang Wu, ${ }^{\#}$ Vladimir Berka, ${ }^{\#}$ Thomas A. Kent, ${ }^{, I, \perp}$ Ah-Lim Tsai, ${ }^{*, \#}$ and James M. Tour, ${ }^{* \dagger, \$, \S}$

${ }^{\dagger}$ Department of Chemistry, ${ }^{\ddagger}$ The NanoCarbon Center, and ${ }^{\S}$ Department of Materials Science and NanoEngineering, Rice University, 6100 Main Street, Houston, Texas 77005, United States

${ }^{\mathrm{I}}$ Center for Translational Research on Inflammatory Diseases, Michael E. DeBakey VA Medical Center, and ${ }^{\perp}$ Department of Neurology, Baylor College of Medicine, Houston, Texas 77030, United States

\#Hematology, Department of Internal Medicine, University of Texas Houston Medical School, Houston, Texas 77030, United States

Supporting Information

ABSTRACT: Hydrophilic carbon clusters (HCCs) are oxidized carbon nanoparticles with a high affinity for electrons. The electron accepting strength of HCCs, employing the efficient conversion of superoxide $\left(\mathrm{O}_{2}{ }^{--}\right)$to molecular oxygen $\left(\mathrm{O}_{2}\right)$ via single-electron oxidation, was monitored using cyclic voltammetry and electron paramagnetic resonance spectroscopy. We found that HCCs possess $\mathrm{O}_{2}$ reduction reaction (ORR) capabilities through a two-electron process with the formation of $\mathrm{H}_{2} \mathrm{O}_{2}$. By comparing results from aprotic solvents to those obtained from ORR activity in aqueous media, we propose a mechanism for the origin of the antioxidant and superoxide dismutase mimetic properties of poly(ethylene glycolated) hydrophilic carbon clusters (PEG-HCCs).

KEYWORDS: superoxide, antioxidant, carbon nanoparticles, oxidation, oxygen reduction

\section{INTRODUCTION}

Superoxide $\left(\mathrm{O}_{2}{ }^{--}\right)$is a radical anion of enormous importance in biology and medicine. $\mathrm{O}_{2}{ }^{\bullet-}$ is generated as a primary byproduct of the partial reduction of $\mathrm{O}_{2}$ during aerobic metabolism and is a key component of the more broadly termed reactive oxygen species (ROS). ${ }^{1-3}$ Other ROS include hydrogen peroxide $\left(\mathrm{H}_{2} \mathrm{O}_{2}\right)$, singlet oxygen, organic peroxides, hydroperoxyl radical $\left(\mathrm{HO}_{2}{ }^{\bullet}\right)$, and hydroxyl radical $\left(\mathrm{HO}^{\bullet}\right)$, which are the products of subsequent proton-coupled reactions. ${ }^{1,4}$ ROS are implicated in many diseases and can cause severe damage to cellular components and metabolism. To protect against ROS, living organisms have developed defensive metalloenzymes such as superoxide dismutase (SOD), peroxidase, and catalase. ${ }^{5-7}$ In addition to enzymes, protection against ROS-induced oxidative stress is provided by antioxidants such as vitamin A, vitamin E, ascorbic acid, uric acid, glutathione, and hydroquinones. ${ }^{8,9}$ Due to the existence of reactive redox coupling of metal ions, SOD has been widely investigated by electrochemical techniques, which has led to the development of various SOD-modified amperometric biosensors for the measurement of $\mathrm{O}_{2}^{\bullet-10,11}$

In addition to the biological importance of the oxygen reduction processes, the cathodic oxygen reduction reaction (ORR) has been an important counterpart and half-reaction in fuel cells. ${ }^{12-14}$ ORR can be a two-electron process, yielding $\mathrm{H}_{2} \mathrm{O}_{2}$, or a four-electron process with the reduction of $\mathrm{O}_{2}$ all the way to $\mathrm{H}_{2} \mathrm{O}$. Synthetic metalloporphyrins are common molecular ORR catalysts inspired by the heme-based cofactors. ${ }^{15}$ However, platinum still remains the first choice as an electrocatalyst for current fuel cells despite its high cost and low abundance. Various SOD-modified catalysts have been investigated for their ORR performances. ${ }^{16}$ The existence of $\mathrm{O}_{2}{ }^{--}$as an intermediate during the ORR has been shown in aprotic solvents. ${ }^{17}$ In our continuing study of carbon-based nanomaterials for applications in both medicine ${ }^{18-23}$ and as metal-free catalysts to convert chemical to electrical energy, ${ }^{24-26}$ we explore here the intersection of the two fundamental carbon-based electrochemical pathways.

We recently developed water-soluble highly oxidized carbon nanomaterials, poly(ethylene glycolated) hydrophilic carbon clusters (PEG-HCCs), that act as highly active mimetics of superoxide dismutase (SOD), a selective antioxidant that dismutases two $\mathrm{O}_{2}{ }^{\bullet-}$ molecules to afford $\mathrm{O}_{2}$ and $\mathrm{H}_{2} \mathrm{O}_{2}$ according to Scheme $1 .{ }^{27}$

Another important feature of PEG-HCCs is their inertness to nitric oxide $\left(\mathrm{NO}^{\bullet}\right)$. Although PEG-HCCs have 1 equiv of stable $\pi$-conjugated carbon radical per highly oxidized carbon core, PEG-HCCs still do not activate $\mathrm{NO}^{\bullet}$ through either

Scheme 1. Mechanism of Catalytic $\mathrm{O}_{2}{ }^{\bullet-}$ Dismutase by PEG$\mathrm{HCCs}^{27}$

$$
\begin{gathered}
\text { PEG-HCC }^{*}+\mathrm{O}_{2}{ }^{-} \rightarrow \text { PEG-HCC }^{-}+\mathrm{O}_{2}(1) \\
\text { PEG-HCC } \\
-\mathrm{O}_{2}{ }^{-{ }^{-}}+2 \mathrm{H}^{+} \rightarrow \text { PEG-HCC }^{*}+\mathrm{H}_{2} \mathrm{O}_{2}(2)
\end{gathered}
$$

Received: March 22, 2016

Accepted: June 1, 2016

Published: June 1, 2016 
radical-radical coupling or single electron transfer processes. When the difference in the redox potentials of $\mathrm{O}_{2}{ }^{\bullet-}$ and $\mathrm{NO}^{\bullet}$ $\left[E^{\circ}\left(\mathrm{O}_{2}{ }^{\bullet-} / \mathrm{O}_{2}\right)=-0.60 \mathrm{~V}\right.$ vs SCE and $E^{\circ}\left(\mathrm{NO}^{\bullet} / \mathrm{NO}^{+}\right)=1.36 \mathrm{~V}$ vs $\mathrm{SCE}$ or $E^{\circ}\left(\mathrm{NO}^{-} / \mathrm{NO}^{\circ}\right)=-1.6 \mathrm{~V}$ vs $\left.\mathrm{SCE}\right]$ is known, ${ }^{28-30}$ it is clear that oxidative single electron transfer activation of $\mathrm{O}_{2}{ }^{\bullet-}$ by PEG-HCCs is thermodynamically more favorable than either oxidative or reductive activation of $\mathrm{NO}^{\bullet}$.

To investigate both the antioxidant and the catalytic properties of HCCs, we sought to analyze the properties of the carbon core of PEG-HCCs, namely HCCs, to address their mechanism for the efficient conversion of $\mathrm{O}_{2}{ }^{\bullet-}$ to $\mathrm{O}_{2}$. HCCs are conjugated graphenic domains with highly oxidized edges. ${ }^{18,19}$ These are then appended to PEG moieties to render them more soluble in commonly used phosphate buffered saline (PBS) and serum and to increase their blood circulation time in vivo. ${ }^{20-23}$ Therefore, the objective of this work was to investigate (a) the oxidizing strength of HCCs by electrochemical analysis of their redox potentials, (b) the reactivity of HCCs with $\mathrm{O}_{2}{ }^{\bullet-}$ in homogeneous conditions (in aprotic solvents), and (c) the ORR activity of the HCC through its immobilization on an electrode acting as a heterogeneous catalyst (in aqueous media).

\section{RESULTS AND DISCUSSION}

Preparation and Characterization of HCCs. Preparation of HCCs was reported earlier. ${ }^{18-20}$ Oxidation of single-walled carbon nanotubes (SWCNTs) under harsh oxidation conditions, employing oleum and fuming nitric acid, resulted in extremely small, water-soluble, generously oxidized and nontubular hydrophilic carbon clusters (Scheme 2). The nanotubes

Scheme 2. Synthesis of HCCs from SWCNTs as the Starting Material
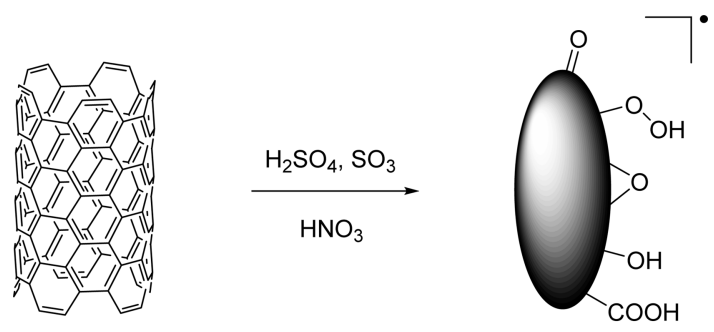

SWCNT

HCC

unzip to give planar graphene-like fragments that are devoid of any radial breathing modes in the Raman spectra. The average size of HCCs is $\sim 3 \mathrm{~nm}$ wide and ranges from 30 to $40 \mathrm{~nm}$ long, and they have been extensively characterized by atomic force microscopy (AFM) and transmission electron microscopy (TEM). ${ }^{18-20}$ Additionally, harsh oxidation conditions facilitated functionalization of HCCs with various oxygen-containing functional groups.

To estimate the extent of the harsh oxidation step and to evaluate the oxygen content and functionality of the HCCs, we characterized HCCs by X-ray photoelectron spectroscopy (XPS). In our previous work, we determined the degree of oxidation of HCCs by identifying the $\mathrm{C} / \mathrm{O}$ ratio in HCCs as $2 /$ 1 (Figure S1). ${ }^{20}$ Here, we report the details of the highresolution XPS spectra (C 1s and O 1s) of the HCCs. Figure 1 shows the $\mathrm{C} 1 \mathrm{~s}$ and $\mathrm{O}$ 1s deconvoluted peaks of HCCs (Figure S1).
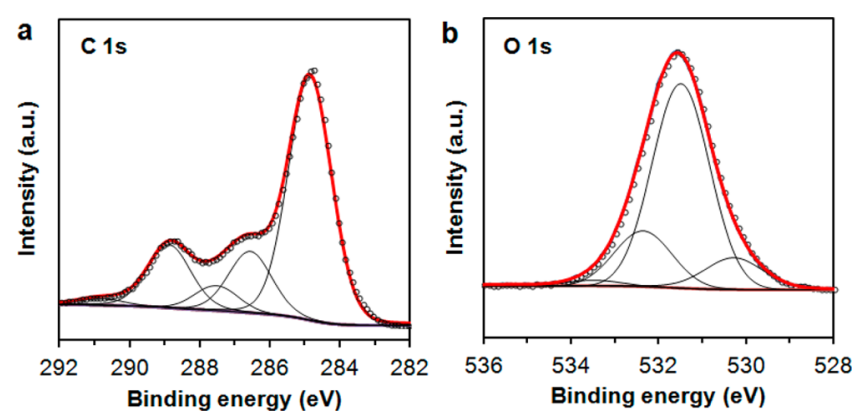

Figure 1. High-resolution deconvoluted XPS of (a) C 1s and (b) O 1s spectra of HCCs.

From the deconvoluted C 1s peaks, it is apparent that the oxygen-containing groups are predominantly in the form of hydroxyl, ether, and epoxy $(\mathrm{C}-\mathrm{O}$ and $\mathrm{C}-\mathrm{O}-\mathrm{C}, 286.6 \mathrm{eV})$ groups. There are also carbonyl $(\mathrm{C}=\mathrm{O}, 287.5 \mathrm{eV})$ groups in the form of ketones or quinones and carboxyl $(\mathrm{HO}-\mathrm{C}=\mathrm{O}$, $288.9 \mathrm{eV}$ ) groups. Note that the spectra were centered at 284.8 $\mathrm{eV}$ for the $\mathrm{sp}^{3}$ - and $\mathrm{sp}^{2}$-hybridized carbons $(\mathrm{C}-\mathrm{C} / \mathrm{C}=\mathrm{C})$. Since the HCCs are heavily oxidized, the contribution from $\mathrm{sp}^{3}$ hybridized carbons are favored. The deconvoluted $\mathrm{O} 1 \mathrm{~s}$ peak of HCCs further shows large amounts of carbonyl and carboxyl $\left(\mathrm{C}=\mathrm{O}\right.$ and $\left.{ }^{-} \mathrm{O}-\mathrm{C}=\mathrm{O}, 531.5 \mathrm{eV}\right)$ groups, and the hydroxyl and ether $(\mathrm{C}-\mathrm{O}$ and $\mathrm{C}-\mathrm{O}-\mathrm{C}, 532.4 \mathrm{eV})$ groups. We have also identified the peak at $530.3 \mathrm{eV}$ as the peroxyl group ( $\mathrm{C}-\mathrm{O}-$ $\mathrm{O})$. Relative contributions of each functional group are summarized in Table S1. In general, from both the C 1s and $\mathrm{O}$ 1s peaks, HCCs show a presence of hydroxyl, ether, carbonyl, and carboxylic groups in large amounts as compared to those in $\mathrm{sp}^{3}$ - and $\mathrm{sp}^{2}$-hybridized carbon $(\mathrm{C}-\mathrm{C} / \mathrm{C}=\mathrm{C})$ groups, indicating the large degree of oxidation of SWCNTs that results from this procedure. It is also noteworthy to mention that the common oxidation procedures for graphene oxide (GO) preparation were not reported to give such a high degree of disrupted $\pi$-conjugated networks during the oxidation of graphene. ${ }^{31}$

Further evidence of the electron-deficient oxygen-containing functional groups was obtained by electrochemical analysis of the HCCs. Figure 2a illustrates the comparison of cyclic voltammograms (CVs) of GO and HCCs in aqueous media at $\mathrm{pH}$ 7.4. The electrochemistry of the electrode-immobilized carbon materials has been reported before, and particularly from the detailed studies on GO, the nature of electrochemically reducible oxygen-functional groups was shown to be dependent on the method of preparation. ${ }^{32}$ Out of four reported GO preparation methods using the Staudenmeier, ${ }^{33}$ Hoffman, ${ }^{34}$ Hummers, ${ }^{35}$ and Tour ${ }^{31}$ procedures, only Staudenmeier's procedure, which employs chlorate as an oxidant in the presence of fuming nitric acid $\left(\mathrm{HNO}_{3}\right)$, produces $\mathrm{GO}$ with a positive reduction wave starting at -0.7 $\mathrm{V}$ and a peak potential at $-1.1 \mathrm{~V}$ vs $\mathrm{Ag} / \mathrm{Ag}^{+}$. All other methods, which use permanganate as the oxidant, exhibit reduction waves for GO starting at $-1.0 \mathrm{~V}$ or below with the peak potentials ranging from $\sim-1.8 \mathrm{~V}$ to $-2.0 \mathrm{~V}$ vs $\mathrm{Ag} / \mathrm{Ag}^{+}$(Figure 2a). ${ }^{31,32}$ From the CV of HCCs (Figure $2 \mathrm{a}$ ) in PBS, which was prepared using the procedure employing only oleum and fuming nitric acid, without an additional oxidant, HCCs have dominant electron-deficient domains that are far more extensive than those seen in GO. HCCs reveal reduction peaks starting at 0.0 $\mathrm{V}$ with the peak maxima at $\sim-0.8 \mathrm{~V}$, which make HCCs stronger oxidants than $\mathrm{GO}$ by an average of almost $1.0 \mathrm{~V}$. 

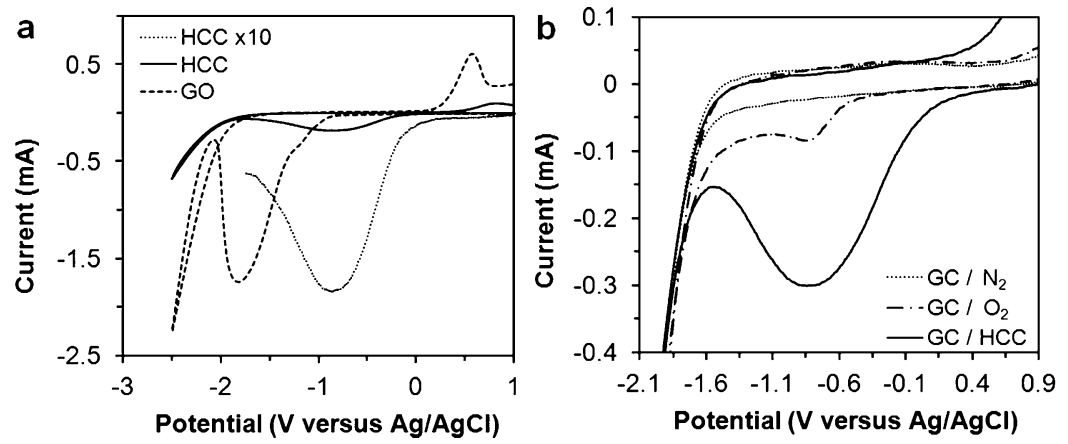

Figure 2. (a) CVs of $50 \mathrm{mM}$ PBS at $\mathrm{pH} 7$ on a bare glassy carbon (GC) working electrode coated with $\mathrm{HCCs}$ or GO recorded under a $\mathrm{N}_{2}$ atmosphere. (b) Comparison of CVs of GC/HCCs (solid line, recorded under a $\mathrm{N}_{2}$ atmosphere), the $\mathrm{O}_{2} / \mathrm{O}_{2}{ }^{\bullet-}$ couple (dot-dash line, $\mathrm{O}_{2}$-saturated buffer), and GC (dotted line, recorded under a $\mathrm{N}_{2}$ atmosphere). Scan rate: $100 \mathrm{mV} / \mathrm{s}$.
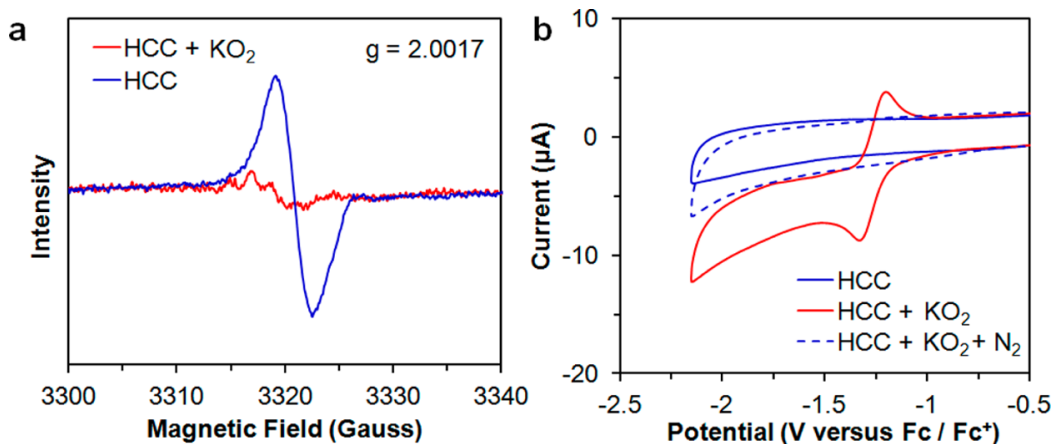

Figure 3. (a) EPR spectra of $0.05 \mathrm{mg} / \mathrm{mL}$ of HCC in DMSO (blue) and after addition of $\mathrm{KO}_{2}$ (red). (b) CVs in DMSO containing $0.1 \mathrm{M}[(n$ $\left.\mathrm{Bu}{ }_{4} \mathrm{~N}\right]^{+} \mathrm{ClO}_{4}^{-}$as a supporting electrolyte at $298 \mathrm{~K}$ at a glassy carbon working electrode with a platinum wire as a quasi-reference electrode. $E(\mathrm{Fc} /$ $\mathrm{Fc}^{+}$) $=0.44$ vs SCE in DMSO. Scan rate: $100 \mathrm{mV} / \mathrm{s}$. HCCs in DMSO under $\mathrm{N}_{2}$ (blue), after addition of $\mathrm{KO}_{2}$ (red), and after bubbling of the resulting solution with $\mathrm{N}_{2}$ for $5 \mathrm{~min}$ to remove any gaseous $\mathrm{O}_{2}$ from the solution (blue broken lines).

Oxygen-containing functional groups show different reduction potentials; specifically, only peroxide and aromatic quinonetype functional groups are reduced at potentials as high as those of HCCs (from 0.0 to $-0.7 \mathrm{~V}$ vs $\mathrm{Ag} / \mathrm{Ag}^{+}$). ${ }^{36,37}$ Therefore, the strong oxidizing properties of HCCs could be due to the presence of both peroxyl and quinone moieties. The presence of peroxyl and quinone groups was also consistent with the XPS analyses shown above.

To estimate the electron accepting strength of HCCs, we compared the reduction potentials of HCCs and $\mathrm{O}_{2}$ (Figure b) in aqueous buffer. Unlike in aprotic solvents, ${ }^{27}$ in aqueous media, due to the disproportionation and proton-transfer processes, $\mathrm{O}_{2}$ exhibits an irreversible reduction wave potential. The reduction wave for $\mathrm{O}_{2}$ corresponds to the reversible oneelectron wave followed by a second irreversible proton-coupled one-electron reduction wave according to eqs 3 and 4:

$$
\begin{aligned}
& \mathrm{O}_{2}+\mathrm{e}^{-} \rightarrow \mathrm{O}_{2}^{\bullet-} \\
& \mathrm{O}_{2}^{\bullet-}+2 \mathrm{H}^{+}+\mathrm{e}^{-} \rightarrow \mathrm{H}_{2} \mathrm{O}_{2}
\end{aligned}
$$

As shown in Figure $2 b$, the $\mathrm{O}_{2}$ reduction wave potentials nicely overlap with the reduction wave potential of HCCs. Hence, the single-electron transfer oxidation of $\mathrm{O}_{2}{ }^{--}$by HCCs is a thermodynamically favorable and exothermic process.

Reactivity of HCCs with Superoxide in Apolar Solvents. In addition to the electron-deficient oxygencontaining functional groups, an HCC also possesses one (on average) stable unpaired radical (Figure 3a) in DMSO as observed previously. ${ }^{27}$ HCCs display an intense and symmetric electron paramagnetic resonance (EPR) signal with $g=2.0017$ with an overall line width of $7 \mathrm{G}$. The sharp and structureless peak implies that $\pi$-delocalization across the extended $\pi$ network of HCCs is limited, and the radical character is more localized in nature. The stable radical character of HCCs is retained after appending the PEG groups to form water-soluble PEG-HCCs. ${ }^{27}$ PEG-HCCs show remarkable selective antioxidant superoxide dismutase-like properties. ${ }^{27}$ The origin of efficient catalytic quenching of $\mathrm{O}_{2}{ }^{\bullet-}$ was correlated to the stable radical species of the carbon core (HCCs) of PEG-HCCs (Figure S2). Consequently, HCCs showed the same behavior as PEG-HCCs toward the quenching of $\mathrm{O}_{2}{ }^{\bullet-}$. The addition of $\mathrm{KO}_{2}$ to the solution of HCCs in dry DMSO resulted in an immediate loss of the EPR signal of HCCs. This implies that HCCs are capable of oxidizing $\mathrm{O}_{2}^{\bullet-}$ with the formation of a reduced and near EPR-silent form of HCCs (Figure 3a). This is the first evidence that the stable intrinsic radical in HCC is capable of redox communication with $\mathrm{O}_{2}{ }^{\bullet-}$.

To further test the single-electron transfer mechanism, we performed electrochemical detection of formed $\mathrm{O}_{2}$ as a second reaction product according to eq 5 .

$$
\mathrm{HCC}^{\bullet}+\mathrm{O}_{2}^{\bullet-} \rightarrow \mathrm{HCC}^{-}+\mathrm{O}_{2}
$$

The electrochemistry of $\mathrm{O}_{2}$ in aprotic solvents is welldocumented and shows a reversible single-electron reduction process to form stable $\mathrm{O}_{2}{ }^{\bullet-38}$ In the presence of a proton source, the $\mathrm{O}_{2} / \mathrm{O}_{2}{ }^{--}$couple loses the reversibility upon the proton-transfer reaction pathways. ${ }^{39}$ This behavior of $\mathrm{O}_{2}{ }^{\bullet-}$ was used to test the antioxidant capacities of various phenols and polyphenols. ${ }^{40}$ A well-dispersed solution of HCCs in anhydrous DMSO with $\left[(n-\mathrm{Bu})_{4} \mathrm{~N}\right]^{+} \mathrm{ClO}_{4}{ }^{-}$as a supporting electrolyte 

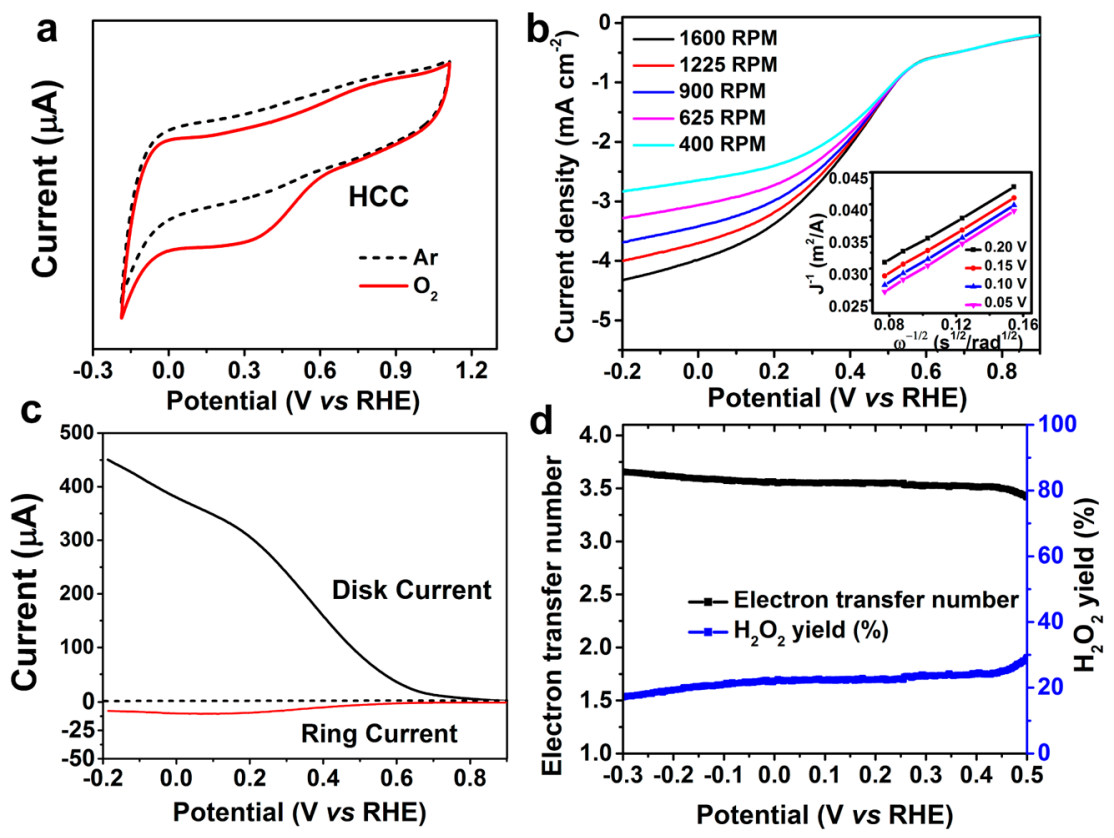

Figure 4. (a) CVs of HCCs under 1 atm $\mathrm{O}_{2}$ or Ar. All scans were collected at $100 \mathrm{mV} \mathrm{s}^{-1}$ using a GC working electrode with an area of $0.196 \mathrm{~cm}^{2}$. (b) LSV curves of RDEVs of HCCs in an $\mathrm{O}_{2}$-saturated $0.1 \mathrm{M} \mathrm{NaHPO}_{4} / \mathrm{NaH}_{2} \mathrm{PO}_{4}$ buffer solution at $\mathrm{pH} 7$ with different rotating speeds ranging from 400 to $1600 \mathrm{rpm}$. Inset: Koutecky-Levich plots of HCCs where $n=3.0$. (c) RRDEV of HCC in a $0.1 \mathrm{M} \mathrm{NaHPO}_{4} / \mathrm{NaH}_{2} \mathrm{PO}_{4}$ buffer solution at pH 7 with a rotation speed of $1600 \mathrm{rpm}$. The disk was scanned from 0.8 to $-0.2 \mathrm{~V}$, while the ring electrode was held at $1.4 \mathrm{~V}$. (d) The number of electrons transferred and the $\mathrm{H}_{2} \mathrm{O}_{2}$ yield of HCCs during the ORR calculated by ring currents.

under an inert atmosphere does not show any noticeable redox peaks associated with the dispersed HCCs (Figure $3 \mathrm{~b}$ ). This outcome indicates that the intrinsic stable radical of an HCC does not respond to the sweeping redox potential field in this aprotic solvent in contrast to that in the aqueous buffer (Figure 2). However, addition of $\mathrm{KO}_{2}$ causes the appearance of a peak at $E^{\circ}=-1.25 \mathrm{~V}$ vs $\mathrm{Fc} / \mathrm{Fc}^{+}$, which is the reversible reduction peak of dissolved $\mathrm{O}_{2}$ that was confirmed by separate measurements in the absence of HCCs. Interestingly, this peak disappears upon bubbling of the resulting solution with $\mathrm{N}_{2}$ for 5 min (Figure $3 b$ ), which confirms the conversion of $\mathrm{O}_{2}{ }^{\bullet-}$ into molecular $\mathrm{O}_{2}$. This is unlike that of the dissolved $\mathrm{O}_{2}{ }^{\bullet-}$, which is persistent in solution even after being bubbled with $\mathrm{N}_{2}$ for $6 \mathrm{~h}$ (Figure S3). Therefore, this measurement further demonstrates that HCCs oxidize $\mathrm{O}_{2}{ }^{\bullet-}$ to $\mathrm{O}_{2}$ through a oneelectron transfer reaction according to eq 5 , and the product, molecular $\mathrm{O}_{2}$, can be observed electrochemically. In addition to $\mathrm{O}_{2}{ }^{\bullet-}$, we also tested the water-soluble perylenedimine radical anion $\left(\mathrm{PEG}^{\mathrm{PDDI}}{ }^{\bullet-}\right.$ ) as a one-electron reductant of $\mathrm{HCCs}$ (Figure S4). A one-electron transfer reaction between $\mathrm{HCC}^{\bullet}$ and PEG-PDI ${ }^{\bullet-}$ takes place only after sonication for $20 \mathrm{~min}$, which could be due to the large difference in the diffusion rates between PEG-PDI ${ }^{\bullet-}$ and $\mathrm{O}_{2}^{\bullet-}$.

ORR Activity of HCCs. To further explore the properties of HCCs, particularly their interactions with $\mathrm{O}_{2}$, we performed electrocatalytic ORR activity tests. HCCs were immobilized on a GC working electrode, which served as an $\mathrm{O}_{2}$-electrode, and tested by $\mathrm{CV}$ and linear sweep voltammetry (LSV) in an $\mathrm{O}_{2}$ saturated $0.1 \mathrm{M} \mathrm{NaHPO} / \mathrm{NaH}_{2} \mathrm{PO}_{4}$ buffer solution at $\mathrm{pH} 7$. CVs over a short potential range are shown in Figure 4a. ORR activity was demonstrated by comparing the CVs under an inert atmosphere and in the presence of $\mathrm{O}_{2}$ (Figure 4a). An Arsaturated electrolyte exhibited weak $\mathrm{CV}$ peaks, but under the $\mathrm{O}_{2}$-saturated electrolyte, a prominent ORR peak with an onset potential at $\sim 0.65 \mathrm{~V}$ vs RHE was observed. The nature of the
ORR peak and activity was evaluated from the estimation of the electron transfer number ( $n$, number of electrons exchanged per oxygen molecule during the ORR) obtained using the Koutecky-Levich (K-L) equations (Figure $4 \mathrm{~b}) .{ }^{41}$ The ORR electron transfer number was determined to be $n=3.0$ at a potential range from -0.10 to $0.20 \mathrm{~V}$, which demonstrates almost equal contribution of two-electron and four-electron reduction pathways with the two-electron oxygen being reduced to $\mathrm{H}_{2} \mathrm{O}_{2}$ (according to eqs 3 and 4) and the fourelectron pathway with complete reduction to water. A mixture of of two- and four-electron pathways for ORR is common for carbon-based nanomaterials. The contribution of the glassy carbon substrate for the two-electron ORR is shown in Figure S5, revealing that the glassy carbon electrode contributes only a small catalytic effect on ORR performance. Though the HCCs are suggested for biomedical applications and not for use in fuel cells, the cycling stability shown in Figure S6 suggests that the catalytic sites are quite stable in the presence of produced aggressive radicals during the ORR.

Rotating disk electrode voltammetry (RDEV) and rotating ring-disk electrode voltammetry (RRDEV) were used to further investigate the mechanism of the $\mathrm{O}_{2}$ reduction, specifically to estimate the potential range of the ORR and determine the yield of $\mathrm{H}_{2} \mathrm{O}_{2}$ during the ORR. Figure $4 \mathrm{c}$ displays the RRDEV of the $\mathrm{O}_{2}$-saturated solution at $1600 \mathrm{rpm}$. The disk current goes through a gradual change when it is scanned from 0.8 to $-0.2 \mathrm{~V}$ (consistent with the voltammograms shown in Figures 4a and $4 \mathrm{~b})$, revealing the ORR activity. At the same time, it is possible to observe the symmetric (with respect to the disk current, Figure 4c) changes in ring current as a function of disk potential. The change in ring current, as a catalytic response, is coupled to the formation of $\mathrm{H}_{2} \mathrm{O}_{2}$ as a product at the disk.

Based on the disk and ring currents in Figure 4, the electron transfer number $(n)$ was 3.5 and the yield of $\mathrm{H}_{2} \mathrm{O}_{2}$ produced was $\sim 25 \%$ according to eq 4 (see the Experimental Section for 
the details of the calculations). Therefore, in addition to the efficient one-electron oxidation of $\mathrm{O}_{2}{ }^{--}$to $\mathrm{O}_{2}$ by HCCs in aprotic media, HCCs catalyze $\mathrm{O}_{2}$ reduction to $\mathrm{H}_{2} \mathrm{O}_{2}$ by a twoelectron process in the presence of a proton source. This work focuses on the oxidizing properties of HCCs and the formation of $\mathrm{H}_{2} \mathrm{O}_{2}$ in a $25 \%$ yield through a two-electron process. Another four-electron transfer process takes place, generating $\mathrm{H}_{2} \mathrm{O}$ in a $75 \%$ yield. ${ }^{14}$ We propose a mechanistic pathway, as shown in Scheme 3, based on the $\mathrm{H}_{2} \mathrm{O}_{2}$-producing behavior of

Scheme 3. ORR Mechanism by HCC

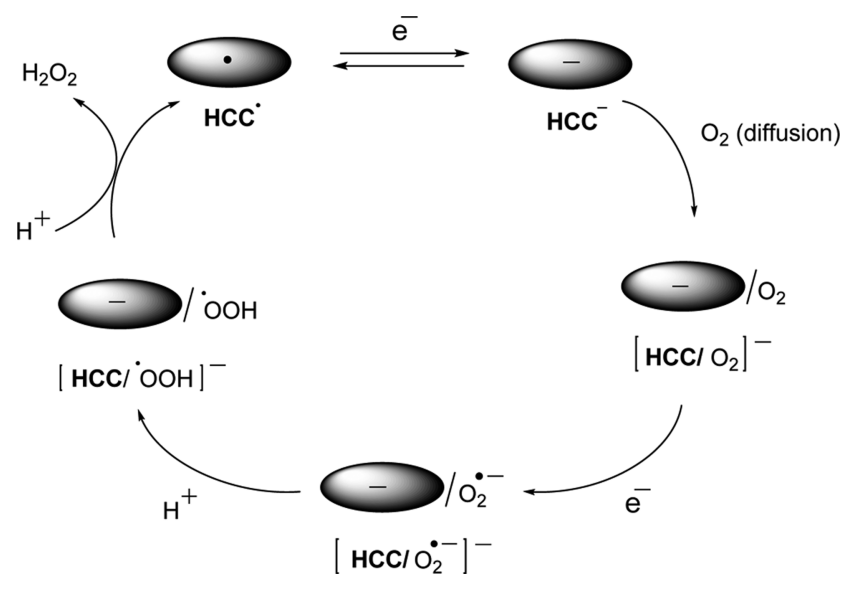

HCCs. Hydrolysis (proton-transfer steps) of the reaction intermediates $\left[\mathrm{HCC} / \mathrm{O}_{2}{ }^{-}\right]^{-}$and $\left[\mathrm{HCC} /{ }^{\bullet} \mathrm{OOH}\right]^{-}$is faster than the two successive electron transfer steps, which shows that the electron transfer steps are the rate-determining steps of the ORR by $\mathrm{HCCs}$ to form $\mathrm{H}_{2} \mathrm{O}_{2}$. We are not certain that this is a biologically relevant scheme for HCCs, but it is seen in electrochemical ORR processes.

These observations suggest that the SOD mimetic activity of PEG-HCCs is linked to the properties of HCCs as oxidants. After the initial electron transfer step from $\mathrm{O}_{2}{ }^{\bullet-}$ to the HCCs, $\mathrm{HCC}^{-}$forms as a reactive intermediate. In the presence of protons, $\mathrm{HCC}^{-}$further proceeds through a fast reaction with another equiv of $\mathrm{O}_{2}{ }^{\bullet-}$, giving rise to $\mathrm{O}_{2}$ and $\mathrm{H}_{2} \mathrm{O}_{2}$ as the final products. The overall SOD-type activity of HCCs is summarized in eq 6, precisely as was predicted by our earlier EPR and stop-flow studies. ${ }^{27}$

$$
\begin{gathered}
\mathrm{HCC}^{\bullet}+\mathrm{O}_{2}^{\bullet-} \rightarrow \mathrm{HCC}^{-}+\mathrm{O}_{2} \\
\mathrm{HCC}^{-}+\mathrm{O}_{2}^{\bullet-}+2 \mathrm{H}^{+} \rightarrow \mathrm{HCC}^{\bullet}+\mathrm{H}_{2} \mathrm{O}_{2} \\
2 \mathrm{O}_{2}^{\bullet-}+2 \mathrm{H}^{+} \rightarrow \mathrm{O}_{2}+\mathrm{H}_{2} \mathrm{O}_{2}
\end{gathered}
$$

\section{CONCLUSIONS}

In summary, the reduction potential of HCCs has been measured to show that HCCs are stronger oxidants than GO. Harsh fuming acid oxidation conditions give rise to increased electron withdrawing functionalities on HCCs. Both $\pi$ conjugated carbon radical centers and electron withdrawing functionalities make HCCs an excellent oxidant to oxidize $\mathrm{O}_{2}{ }^{\bullet-}$ to $\mathrm{O}_{2}$ in aprotic solvent by a single-electron transfer mechanism. To assess the importance of subsequent protoncoupled steps, HCCs were immobilized on a GC working electrode, and the electrocatalytic reduction of $\mathrm{O}_{2}$ to $\mathrm{H}_{2} \mathrm{O}_{2}$ in a neutral aqueous environment was demonstrated. The ORR electrocatalysis by HCC was indicated to proceed with an electron transfer number of 3.5. RRDEV of HCCs shows the production of $\mathrm{H}_{2} \mathrm{O}_{2}$ in a $\sim 25 \%$ yield, indicating that protoncoupled hydrolysis of electron transfer intermediates is much faster than that in the electron transfer steps. Thus, electron transfer steps are the rate-determining steps.

To obtain a good analogue for PEG-HCCs with very high SOD activity, we need to have its redox potential located between those of the two half reactions: $\mathrm{O}_{2}{ }^{\bullet-}$ oxidation to $\mathrm{O}_{2}$ and $\mathrm{O}_{2}{ }^{--}$reduction to $\mathrm{H}_{2} \mathrm{O}_{2}(-0.16$ and $0.94 \mathrm{~V}$, respectively, relative to NHE in water). In this study, we demonstrated that HCCs meet redox requirements for $\mathrm{O}_{2}{ }^{\bullet-}$ oxidation to $\mathrm{O}_{2}$ in DMSO and aqueous buffer. To fully meet the expectation for both of the half reactions, synthetic small molecule analogues of HCCs and PEG-HCCs are currently being constructed and tested. The reactivity of the $\mathrm{HCC}$ intrinsic radical toward $\mathrm{O}_{2}{ }^{\bullet-}$ in DMSO observed in this study (Figure 3) is encouraging and suggests its relevance in this process. Transient kinetic measurements by rapid-freeze quench EPR for the direct reaction between PEG-HCCs and $\mathrm{O}_{2}{ }^{--}$in aqueous buffer are also under careful study to assess if this intrinsic radical indeed participates in the actual chemical steps of the catalytic mechanism.

\section{EXPERIMENTAL SECTION}

Materials. All chemicals were purchased from Sigma-Aldrich and used without further purification unless otherwise stated. SWCNTs (batch HPR 187.4) were obtained from the HiPco Laboratory at Rice University

Electrochemistry. CVs were obtained with a CHI1202 ElectroChemical Analyzer ( $\mathrm{CH}$ Instruments) of $10 \mathrm{~mL}$ samples of electrolyte solutions $\left(0.1 \mathrm{M}\left[(n-\mathrm{Bu})_{4} \mathrm{~N}\right] \mathrm{ClO}_{4}\right.$ solution in DMSO or PBS buffer, $\mathrm{pH}$ 7.4) using a three-electrode cell. A GC electrode served as the working electrode, platinum wires served as the counter electrode, and $\mathrm{Ag} / \mathrm{AgCl}$ served as the reference electrode. A platinum wire was used as the pseudoreference electrode in DMSO; ferrocene $(\mathrm{Fc})$ was used as the internal potential standard, and all potentials were referred to the $\mathrm{Fc} / \mathrm{Fc}^{+}$couple. $\mathrm{CVs}$ were recorded at a scan rate of $100 \mathrm{mV} \mathrm{s}^{-1}$.

RDE and RRDE experiments were conducted in an electrochemical cell (AutoLab PGSTST302) using a rotator (Pine Instrument, AFMSRCE) connected to an electrochemical analyzer ( $\mathrm{CH}$ Instruments, 600D) with an $\mathrm{Ag} / \mathrm{AgCl}$ reference electrode and a Pt wire counter electrode. An HCC ink solution was prepared by dispersing 4 mg of HCCs into $1 \mathrm{~mL}$ of $4 / 1 \mathrm{DCM} / \mathrm{EtOH}$ solvent, and $8 \mu \mathrm{L}$ of the catalyst ink solution was loaded onto a GC electrode $(5 \mathrm{~mm}$ in diameter). Constant bubbling by a stream of $\mathrm{O}_{2}$ in the cell solution was maintained throughout the measurements to ensure continuous $\mathrm{O}_{2}$ saturation. Measurements were carried out at $\mathrm{pH} 7(0.1 \mathrm{M}$ $\mathrm{K}_{2} \mathrm{HPO}_{4} / \mathrm{KH}_{2} \mathrm{PO}_{4}$ buffer). For RRDE experiments, the electrode rotation speed was $1600 \mathrm{rpm}$ (scan rate: $0.05 \mathrm{~V} / \mathrm{s}$; platinum data collected from anodic sweeps), while the ring electrode potential was held at $1.1 \mathrm{~V}$ vs the reversible hydrogen electrode (RHE).

The $\mathrm{O}_{2}$ reduction current increases with increasing rotation rates following $\mathrm{K}-\mathrm{L}$ eq 7 :

$$
J^{-1}=J_{\mathrm{K}}^{-1}+J_{\mathrm{L}}^{-1}
$$

where $J_{\mathrm{K}}$ is the potential dependent kinetic current and $J_{\mathrm{L}}$ is the Levich current. $J_{\mathrm{L}}$ is expressed as $0.62 n F\left[\mathrm{O}_{2}\right]\left(D_{\mathrm{O} 2}\right)^{2 / 3} \omega^{1 / 2} \nu^{-1 / 6}$, where $n$ is the number of electrons transferred to the substrate, $F$ is the Faraday constant, $\left[\mathrm{O}_{2}\right]$ is the concentration of $\mathrm{O}_{2}$ in an air-saturated buffer $(0.22 \mathrm{mM}$ in the case of $\mathrm{pH} 7)$ at $25{ }^{\circ} \mathrm{C}, D_{\mathrm{O} 2}$ is the diffusion coefficient of $\mathrm{O}_{2}\left(1.8 \times 10^{-5} \mathrm{~cm}^{2} \mathrm{~s}^{-1}\right.$ at $\left.\mathrm{pH} 7\right)$ at $25{ }^{\circ} \mathrm{C}, \omega$ is the angular velocity of the disc, and $\nu$ is the kinematic viscosity of the solution $\left(0.009 \mathrm{~cm}^{2} \mathrm{~s}^{-1}\right)$ at $25{ }^{\circ} \mathrm{C}$. When eq 7 is rewritten as eq 8 and solved for $J_{\mathrm{L}}$, it gives eq 9: 


$$
\begin{aligned}
& \frac{1}{J}=\frac{1}{J_{\mathrm{K}}}+\frac{1}{J_{\mathrm{L}}} \\
& J_{\mathrm{L}}=0.62 n F\left[\mathrm{O}_{2}\right]\left(D_{\mathrm{O} 2}\right)^{2 / 3} \omega^{1 / 2} v^{-1 / 6}
\end{aligned}
$$

RRDE measurements were carried out to determine the $\mathrm{H}_{2} \mathrm{O}_{2}$ yield (\%) and $n$, which were calculated by eqs 10 and 11 :

$$
\begin{aligned}
& \mathrm{H}_{2} \mathrm{O}_{2} \%=\left(200 i_{\mathrm{r}} / N\right) /\left(i_{\mathrm{d}}+i_{\mathrm{r}} / N\right) \\
& n=4 i_{\mathrm{d}} /\left(i_{\mathrm{d}}+i_{\mathrm{r}} / N\right)
\end{aligned}
$$

where $i_{\mathrm{d}}$ and $i_{\mathrm{r}}$ are the disk and ring currents, respectively. $N$ is the ring current collection efficiency which was determined to be $25 \%$ by the reduction of $10 \mathrm{mM} \mathrm{K}_{3}\left[\mathrm{Fe}(\mathrm{CN})_{6}\right]$ in $0.1 \mathrm{M} \mathrm{KNO}_{3}$.

XPS. XPS spectra were obtained on a PHI Quantera SXM scanning $\mathrm{X}$-ray microprobe system using a $100 \mu \mathrm{m}$ X-ray beam with a takeoff angle of $45^{\circ}$ and a pass energy of $140 \mathrm{eV}$ for the survey and $26 \mathrm{eV}$ for the high-resolution elemental analysis.

Detection of Radicals by EPR Spectroscopy. EPR spectra of HCCs $(0.05 \mathrm{mg} / \mathrm{mL}$ in DMSO) in a capillary tube at ambient temperature were recorded using the following parameters: center field $3320 \mathrm{G}$, sweep width $50 \mathrm{G}$, microwave frequency $9.3 \mathrm{GHz}$, microwave power $1 \mathrm{~mW}$, modulation frequency $100 \mathrm{kHz}$, and modulation amplitude $1.0 \mathrm{G}$. The same sample was remeasured after adding a small amount of $\mathrm{KO}_{2}(1 \mathrm{mg}$ in powder form).

\section{ASSOCIATED CONTENT}

\section{S Supporting Information}

The Supporting Information is available free of charge on the ACS Publications website at DOI: 10.1021/acsami.6b03502.

Additional X-ray photoelectron spectra of HCCs, dependence of intrinsic radical on SOD activity of PEG-HCCs, CV of $\mathrm{KO}_{2}$ in dry DMSO, HCCs as oxidants of the PEG-PDI radical anion, contribution of GC to ORR activity, and stability of HCCs (PDF)

\section{AUTHOR INFORMATION}

\section{Corresponding Authors}

*E-mail: ah-lim.tsai@uth.tmc.edu.

*E-mail: tour@rice.edu.

\section{Notes}

The authors declare the following competing financial interest: Acelerox LLC has licensed several pieces of intellectual property from Rice University regarding the therapeutic use of carbon nanoparticles as antioxidants. J.M.T. and T.A.K. are stockholders in that company, though they are not directors or officers. Conflicts are managed by disclosures to the respective institutions' Offices of Compliance.

\section{ACKNOWLEDGMENTS}

We thank the NIH (Grants R01-NS094535 and R21NS084290) and the Dunn Foundation for financial support.

\section{REFERENCES}

(1) Halliwell, B. Reactive Oxygen Species in Living Systems: Source, Biochemistry, and Role in Human Disease. Am. J. Med. 1991, 91, 14S22S.

(2) Valentine, J. S.; Wertz, D. L.; Lyons, T. J.; Liou, L. L.; Goto, J. J.; Gralla, E. B. The Dark Side of Dioxygen Biochemistry. Curr. Opin. Chem. Biol. 1998, 2, 253-262.

(3) Bandyopadhyay, U.; Das, D.; Banerjee, R. K. Reactive Oxygen Species: Oxidative Damage and Pathogenesis. Curr. Sci. 1999, 77, $658-666$.
(4) Dickinson, B. C.; Chang, C. J. Chemistry and Biology of Reactive Oxygen Species in Signaling or Stress Responses. Nat. Chem. Biol. 2011, 7, 504-511.

(5) Miller, A. F. Superoxide Dismutases: Active Sites that Save, But a Protein that Kills. Curr. Opin. Chem. Biol. 2004, 8, 162-168.

(6) Banci, L. Structural Properties of Peroxidases. J. Biotechnol. 1997, $53,253-263$.

(7) Chelikani, P.; Fita, I.; Loewen, P. C. Diversity of Structures and Properties Among Catalases. Cell. Mol. Life Sci. 2004, 61, 192-208.

(8) Liu, Z. Q. Chemical Methods to Evaluate Antioxidant Ability. Chem. Rev. 2010, 110, 5675-5691.

(9) Ingold, K. U.; Pratt, D. A. Advances in Radical-Trapping Antioxidant Chemistry in the 21st Century: A Kinetics and Mechanisms Perspective. Chem. Rev. 2014, 114, 9022-9046.

(10) Lvovich, V.; Scheeline, A. Amperometric Sensors for Simultaneous Superoxide and Hydrogen Peroxide Detection. Anal. Chem. 1997, 69, 454-462.

(11) Electrochemical Sensors, Biosensors and Their Biomedical Applications; Zhang, X., Ju, H., Wang, J., Eds. Elsevier, 2008.

(12) Zhang, J. PEM Fuel Cell Electrocatalysts and Catalyst Layers: Fundamentals and Applications; Springer-Verlag London Ltd: London, U.K., 2008; Chapter 2, pp 89-135.

(13) Chabot, V.; Higgins, D.; Yu, A.; Xiao, X.; Chen, Z.; Zhang, J. A. Review of Graphene and Graphene Oxide Sponge: Materials Synthesis and Applications to Energy and the Environment. Energy Environ. Sci. 2014, 7, 1564-1596.

(14) Dai, L.; Xue, Y.; Qu, L.; Choi, H. J.; Baek, J. B. Metal-Free Catalysts for Oxygen Reduction Reaction. Chem. Rev. 2015, 115, 4823-4892.

(15) Boulatov, R. Metalloporphyrin Catalysts for Oxygen Reduction. In Fuel Cell Catalysis: A Surface Science Approach; Koper, M. T., Ed.; John Wiley \& Sons: Hoboken, NJ, 2009; pp 637- 693.

(16) Ding, K.; Zhao, M.; Wang, Q. Catalysis of the Electrochemical Oxygen Reduction in Room-Temperature Ionic Liquids on a Pyrolytic Graphite Electrode by Iron-Containing Superoxide Dismutase. Russ. J. Electrochem. 2007, 43, 1082-1090.

(17) Carter, M. T.; Hussey, C. L.; Strubinger, S. K. D.; Osteryoung, R. A. Electrochemical Reduction of Dioxygen in Room-Temperature Imidazolium Chloride-Aluminum Chloride Molten Salts. Inorg. Chem. 1991, 30, 1149-1151.

(18) Chen, Z.; Kobashi, K.; Rauwald, U.; Booker, R.; Fan, H.; Hwang, W. - F.; Tour, J. M. Soluble Ultra-Short Single-Walled Carbon Nanotubes. J. Am. Chem. Soc. 2006, 128, 10568-10571.

(19) Lucente-Schultz, R. M.; Moore, V. C.; Leonard, A. D.; Price, K. B.; Kosynkin, D. V.; Lu, M.; Partha, R.; Conyers, J. L.; Tour, J. M. Antioxidant Single-Walled Carbon Nanotubes. J. Am. Chem. Soc. 2009, 131, 3934-3941.

(20) Berlin, J. M.; Leonard, A. D.; Pham, T. T.; Sano, D.; Marcano, D. C.; Yan, S.; Fiorentino, S.; Milas, Z. L.; Kosynkin, D. V.; Price, B. K.; Lucente-Schultz, R. M.; Wen, X. X.; Raso, M. G.; Craig, S. L.; Tran, H. T.; Myers, J. N.; Tour, J. M. Effective Drug Delivery, In Vitro and In Vivo, by Carbon-Based Nanovectors Noncovalently Loaded with Unmodified Paclitaxel. ACS Nano 2010, 4, 4621-4636.

(21) Sano, D.; Berlin, J. M.; Pham, T. T.; Marcano, D. C.; Valdecanas, D. R.; Zhou, G.; Milas, L.; Myers, J. N.; Tour, J. M. Noncovalent Assembly of Targeted Carbon Nanovectors Enables Synergistic Drug and Radiation Cancer Therapy In Vivo. ACS Nano 2012, 6, 2497-2505.

(22) Bitner, B. R.; Marcano, D. C.; Berlin, J. M.; Fabian, R. H.; Cherian, L.; Culver, J. C.; Dickinson, M. E.; Robertson, C. S.; Pautler, R. G.; Kent, T. A.; Tour, J. M. Antioxidant Carbon Particles Improve Cerebrovascular Dysfunction Following Traumatic Brain Injury. ACS Nano 2012, 6, 8007-8014.

(23) Samuel, E. L. G.; Duong, M. L. T.; Bitner, B. R.; Kent, T. A.; Tour, J. M. Hydrophilic Carbon Clusters as Therapeutic, HighCapacity Antioxidants. Trends Biotechnol. 2014, 32, 501-505.

(24) Gong, Y.; Fei, H.; Zou, X.; Zhou, W.; Yang, S.; Ye, G.; Liu, Z.; Peng, Z.; Lou, J.; Vajtai, R.; Yakobson, B. I.; Tour, J. M.; Ajayan, P. M. Boron- and Nitrogen-Substituted Graphene Nanoribbons as Efficient 
Catalysts for Oxygen Reduction Reaction. Chem. Mater. 2015, 27, $1181-1186$.

(25) Fei, H.; Ye, R.; Ye, G.; Gong, Y.; Peng, Z.; Fan, X.; Samuel, E. L. G.; Ajayan, P. M.; Tour, J. M. Boron- and Nitrogen-Doped Graphene Quantum Dots/Graphene Hybrid Nanoplatelets as Efficient Electrocatalysts for Oxygen Reduction. ACS Nano 2014, 8, 10837-10843.

(26) Zhu, Y.; James, D. K.; Tour, J. M. New Routes to Graphene, Graphene Oxide and Their Related Applications. Adv. Mater. 2012, 24, 4924-4955.

(27) Samuel, E. L. G.; Marcano, D. C.; Berka, V.; Bitner, B. R.; Wu, G.; Potter, A.; Fabian, R. H.; Pautler, R. G.; Kent, T. A.; Tsai, A.-L.; Tour, J. M. Highly Efficient Conversion of Superoxide to Oxygen Using Hydrophilic Carbon Clusters. Proc. Natl. Acad. Sci. U. S. A. 2015, 112, 2343-2348.

(28) Sawyer, D. T.; Valentine, J. S. How Super is Superoxide? Acc. Chem. Res. 1981, 14, 393-400.

(29) Rosokha, S. V.; Kochi, J. K. Fresh Look at Electron-Transfer Mechanisms via the Donor/Acceptor Bindings in the Critical Encounter Complex. Acc. Chem. Res. 2008, 41, 641-653.

(30) Bartberger, M. D.; Liu, W.; Ford, E.; Miranda, K. M.; Switzer, C.; Fukuto, J. M.; Farmer, P. J.; Wink, D. A.; Houk, K. N. The Reduction Potential of Nitric Oxide (NO) and its Importance to NO Biochemistry. Proc. Natl. Acad. Sci. U. S. A. 2002, 99, 10958-10963.

(31) Marcano, D. C.; Kosynkin, D. V.; Berlin, J. M.; Sinitskii, A.; Sun, Z.; Slesarev, A.; Alemany, L. B.; Lu, W.; Tour, J. M. Improved Synthesis of Graphene Oxide. ACS Nano 2010, 4, 4806-4814.

(32) Eng, A. Y. S.; Ambrosi, A.; Chua, C. K.; Sanek, F.; Sofer, Z.; Pumera, M. Unusual Inherent Electrochemistry of Graphene Oxides Prepared Using Permanganate Oxidants. Chem. - Eur. J. 2013, 19, 12673-12683.

(33) Staudenmaier, L. Verfahren zur Darstellung der Graphitsäure. Ber. Dtsch. Chem. Ges. 1898, 31, 1481-1487.

(34) Hofmann, U.; Konig, E. Analysis of Graphite Dioxide. Z. Anorg. Allg. Chem. 1937, 234, 311-336.

(35) Hummers, W. S.; Offeman, R. E. Preparation of Graphitic Oxide. J. Am. Chem. Soc. 1958, 80, 1339-1339.

(36) Stuart, E. J. E.; Pumera, M. Nanographite Impurities within Carbon Nanotubes are Responsible for Their Stable and Sensitive Response Toward Electrochemical Oxidation of Phenols. J. Phys. Chem. C 2011, 115, 5530-5534.

(37) Peng, X. Y.; Liu, X. X.; Diamond, D.; Lau, K. T. Synthesis of Electrochemically-Reduced Graphene Oxide Film With Controllable Size and Thickness and its Use in Supercapacitor. Carbon 2011, 49, 3488-3496.

(38) Sawyer, D. T. Oxygen Chemistry; Oxford University Press: New York, 1991.

(39) Costentin, C.; Evans, D. H.; Robert, M.; Savéant, J.-M.; Singh, P. S. Electrochemical Approach to Concerted Proton and Electron Transfers. Reduction of the Water-Superoxide Ion Complex. J. Am. Chem. Soc. 2005, 127, 12490-12491.

(40) Rene, A.; Abasq, M.; Hauchard, D.; Hapiot, P. How Do Phenolic Compounds React toward Superoxide Ion? A Simple Electrochemical Method for Evaluating Antioxidant Capacity. Anal. Chem. 2010, 82, 8703-8710.

(41) Treimer, S.; Tang, A.; Johnson, D. C. A Consideration of the Application of Koutecky-Levich Plots in the Diagnosis of ChargeTransfer Mechanisms at Rotated Disk Electrodes. Electroanalysis 2002, 14, 165-171. 